\title{
Evaluation of the taxonomic status of water dropwort (Oenanthe, Apiaceae) accessions from East Asia based on nuclear rDNA internal transcribed spacer sequences
}

\author{
S. Fu' ${ }^{1}$, L.N. Li ${ }^{2}$, Z.C. Long' ${ }^{2}$, W.D. Ke ${ }^{3}$, A.H. Ye ${ }^{3}$, Y.H. Guo ${ }^{1}$ and J.M. Chen ${ }^{2}$ \\ ${ }^{1}$ Laboratory of Plant Systematics and Evolutionary Biology, \\ College of Life Sciences, Wuhan University, Wuhan, Hubei, China \\ ${ }^{2}$ Key Laboratory of Aquatic Botany and Watershed Ecology, \\ Wuhan Botanical Garden, Chinese Academy of Sciences, Wuhan, Hubei, China \\ ${ }^{3}$ Wuhan Vegetable Scientific Research Institute, \\ Wuhan National Field Observation and Research Station for Aquatic Vegetables, \\ Wuhan, China \\ Corresponding authors: Y.H. Guo / J.M. Chen \\ E-mail: yhguo@whu.edu.cn / jmchen@wbgcas.cn
}

Genet. Mol. Res. 15 (2): gmr.15027363

Received August 5, 2015

Accepted November 13, 2015

Published April 25, 2016

DOI http://dx.doi.org/10.4238/gmr.15027363

\begin{abstract}
Oenanthe L. is a taxonomically complex genus, several species of which have long been used as vegetables and traditional medicines in East Asia. In order to clarify the taxonomic status of Oenanthe accessions and provide baseline data for the sustainable use of its genetic resources, we examined sequence variations in the internal transcribed spacer (ITS) region of Oenanthe accessions collected from a wide geographical area in China and its neighboring countries. For comparison, ITS sequences in GenBank for almost all currently reported species of Oenanthe were also included in our analyses. Both phylogenetic tree construction methods (Bayesian inference and maximum likelihood) revealed that the accessions tended to cluster
\end{abstract}


into two groups, which were closely related to $O$. mildbraedii and $O$. sarmentosa. However, these two species have never been recorded in China or its neighboring countries. Therefore, it seems probable that in our sampled locations, Oenanthe accessions have been given an incorrect name, such as O. javanica. Future studies should carefully check the morphological characteristics of other Oenanthe species and sequence their ITS regions in order to clarify the taxonomic status of the genus.

Key words: East Asia; nrDNA ITS; Oenanthe; Taxonomy; Water dropwort

\section{INTRODUCTION}

The genus Oenanthe L. ("water dropwort", Apiaceae) includes about 30 species that are widely distributed in Eurasia, North America, and Africa (Fu and Watson, 2005). Oenanthe is a taxonomically complex genus due to its diverse morphology and widespread dispersal (Fu and Watson, 2005; Zhao, 2010; Spalik et al., 2014). In the last decade, great progress has been made in elucidating high-level phylogenetic relationships within the family Apiaceae, including Oenanthe, such as the tribe Oenantheae (Downie et al., 2008; Spalik et al., 2009, 2014) and the subfamily Apioideae (Downie and Katz-Downie, 1999; Zhou et al., 2008, 2009) by polymerase chain reaction (PCR) and direct DNA sequencing. The phylogenetic position of Oenanthe in Apiaceae has been studied extensively in these studies. However, they only used a few representative species of Oenanthe from a limited geographical region. Only a few studies have investigated the phylogenetic relationships between species (Spalik et al., 2014) and genetic variation within species (Huh et al., 2002; Zhao, 2010) in Oenanthe; therefore, the taxonomic status of Oenanthe species remains unclear.

Oenanthe species have long been used in East Asia as vegetables and as traditional medicines (Fu and Watson, 2005; Zhao, 2010; Su et al., 2011). The fresh leaves and petioles of Oenanthe plants contain high levels of proteins, amino acids, calcium, Vitamin C, iron, and flavonoids (Liu et al., 2007; Zhao, 2010). One of the most widely utilized species is $O$. javanica, which has been cultivated and used in China, Japan, Korea, and Southeast Asia for thousands of years (Huh et al., 2002; Zhao, 2010). Assessing the taxonomic status of germplasm resources is essential for the sustainable use of crops and medicinal materials. However, due to the morphological variability of these germplasms, the evaluation of their taxonomic status is still limited in many geographical regions.

In the Chinese version of the "Flora of China", nine species and one variety of Oenanthe are recorded (China Flora Editorial Board of CAS, 1985). In a later revision of this genus in an English version of the "Flora of China", Fu and Watson (2005) treated these taxa as only five species (O. javanica, $O$. benghalensis, $O$. hookeri, $O$. linearis, and $O$. thomsonii) and six subspecies, based on a re-examination of their morphological characteristics. Although several species, such as $O$. benghalensis, $O$. hookeri, and $O$. linearis, might have been cultivated and used as vegetables and medicines in different regions of China, in our field investigations we found that these germplasm resources were still regarded as $O$. javanica by local people and even the researchers. To date, only a few phylogenetic studies have included Oenanthe accessions from China (Zhou et al., 2008; Zhao, 2010). For example, Zhou et al. 
(2008) sampled only six accessions, representing four species of Oenanthe, in their molecular phylogenetic study of the Chinese Apiaceae subfamily Apioideae; Zhao (2010) studied the genetic diversity and phylogenetic relationships of 20 cultivated accessions of the species "O. stolonifera", which is a synonym of $O$. javanica, using random amplified polymorphic DNA (RAPD) molecular markers. As suggested by Fu and Watson (2005), studies over a wide geographical area are still needed to resolve the classification.

The nuclear ribosomal DNA internal transcribed spacer (nrDNA ITS) region has been suggested to be the core barcode for the species discrimination of seed plants (Li et al., 2011). The ITS region has also been successfully used for low-level phylogenetic analyses in the Apiaceae (Downie et al., 2001, 2008; Kadereit and Kadereit, 2005; Zhou et al., 2008, 2009; Spalik et al., 2009). The numerous ITS sequences available in GenBank for almost all currently reported species of Oenanthe provide a reference for species discrimination. In the present study, we used the ITS region as a molecular marker to examine the sequence variation of Oenanthe accessions collected from a wide geographical area in China and its neighboring countries, i.e., North Korea, Japan, and Vietnam. Our main objectives were to evaluate the taxonomic status of these accessions and provide baseline data for the sustainable use of these plant genetic resources.

\section{MATERIAL AND METHODS}

\section{Sampling}

In total, 170 accessions of Oenanthe from East Asia were sequenced and examined for ITS sequence variation, including 165 accessions from 15 provinces of China, two accessions from North Korea, one from Japan, and two from Vietnam (Table 1). Each accession was collected from a different location in each country (Figure 1). Leaf material was collected from each accession, and leaf samples were stored in silica gel until DNA extraction. Vouchers for all of the sampled accessions were deposited in the Herbarium of Wuhan Vegetable Scientific Research Institute, Wuhan, China. To infer phylogenetic relationships between the accessions sampled in this study and other species within the Oenanthe, we downloaded the ITS sequences of 43 Oenanthe accessions of 29 species from GenBank, which represented nearly all currently recorded species of this genus (Table 2). In addition, two species (Cicuta virosa, GenBank accession No. AY524767 and C. maculate, AY524733) from the genus Cicuta were selected as outgroups in phylogenetic tree reconstructions, according to previous phylogenetic studies (Downie et al., 2008; Zhou et al., 2008; Spalik et al., 2009, 2014).

\section{DNA extraction, PCR amplification, and sequencing}

Total genomic DNA was extracted from dry leaf material using a Plant Genomic DNA Kit (Tiangen, Beijing, China) following the manufacturer instructions. DNA concentrations were estimated and standardized on $2.0 \%(\mathrm{w} / \mathrm{v})$ agarose gels.

The ITS regions, including ITS-1, 5.8S rDNA, and ITS-2, were amplified by PCR using the primers "ITS4" and "ITS5" (for the primer sequences, see White et al., 1990). PCR amplifications in $50-\mu \mathrm{L}$ reactions were conducted with the following reagents: $0.25 \mathrm{mM}$ of each dNTP, $5 \mu \mathrm{L}$ 10X Taq buffer (10 mM Tris-HCl, pH 8.3, $1.5 \mathrm{mM} \mathrm{MgCl}_{2}$, and $50 \mathrm{mM} \mathrm{KCl}$ ), $1 \mathrm{mM}$ of each primer, $2 \mathrm{U}$ Taq Polymerase (Sangon Biotech, Shanghai, China); a total of 6080 ng genomic DNA was added to each reaction. The amplifications were conducted in an 
Table 1. Locations and haplotypes of 170 Oenanthe accessions (V11E-01-V11E-170).

\begin{tabular}{|c|c|c|}
\hline $\begin{array}{ll}\text { Region } \\
\text { Ching }\end{array}$ & Accession, location, and haplotype & GenBank accession \\
\hline \multirow{5}{*}{$\begin{array}{l}\text { China } \\
\text { Anhui }\end{array}$} & & Hapl: KT362845 \\
\hline & V11E-01 (XC, Hapl), V11E-03 (HN, Hap16), V11E-06 (TC1, Hap1), V11E-10 (QS, Hap17), V11E-12 (SX, Hap19), V11E-13 (QY, Hap16), V11E-17 (LJ1, Hap1), & Hap2: KT362846 \\
\hline & V11E-18 (CZ, Hap17), V11E-21 (CH, Hap1), V11E-36 (AQ, Hap24), V11E-38 (NL, Hap1), V11E-42 ( & Нар3: КТ362847 \\
\hline & V11E-67 (HF1, Hap1), V1 IE-69 (SC2, Hap1), V11E-70 (SC3, Hap1), V11E-72 (HF2, Hap1), V11E-73 (LJ3, Hap31), V11E-74 (LJ4, Hap1), V11E-76 (WH1, Ha & Нар4: КТ362848 \\
\hline & $\begin{array}{l}\text { V11E-100 (TC2, Hapl), V11E-101 (TC3, Hapl), V11E-108 (WH2, Hap1), V11E-121 (WH3, Hap9), V11E-133 (LJ5, Hap39), V11E-138 (LJ6, Ha } \\
\text { (TC4, Hap43) }\end{array}$ & Hap5 КT362849 \\
\hline Fujian & V11E-09 (WYS1, Hap1), V11E-89 (WYS2, Hapl) & $\begin{array}{l}\text { Hap6: К K1362850 } \\
\text { Hap7: КT362851 }\end{array}$ \\
\hline Guangxi & V11E-65 (LZ, Hap1), V11E-87 (GL, Hap2) & Hap8: KT362852 \\
\hline \multirow[t]{2}{*}{ Guizhou } & V11E-02 (BJl, Hap12), V11E-11 (AS1, Hap18), V11E-14 (GY1, Hapl), V11E-15 (QX, Hapl), V11E-16 (ZY1, Hap12), V11E-19 (BJ2, Hap12), V11E- & Hар9: КT362853 \\
\hline & Hapl), V1lE-88 (AS2, Hapl), V1lE-92 (ZY2, Hap24), V11E-103 (ZY3, Hapl), V1lE-124 (AS3, Hapl), V11E-146 (GY2, Hapl), V1lE-158 (AS4, Hap44) & $\begin{array}{l}\text { Hap10: KT362854 } \\
\text { Hap11: KT362855 }\end{array}$ \\
\hline Hainan & V11E-71 (QH, Hap30) & Hapl2: KT362856 \\
\hline Henan & $\begin{array}{l}\text { V11E-78 (XY1, Hap33), V11E-125 (NY, Hap1), V11E- } 126 \text { (XY2, Hap10), V11E-141 (WY, Hap12), V1 1E-142 (PDS, Hap12), V1 IE-163 (HY, Hap48), V11E-52 } \\
\text { (SQ, Hapl) }\end{array}$ & $\begin{array}{l}\text { Hap13: KT362857 } \\
\text { Hap14: KT362858 }\end{array}$ \\
\hline \multirow[t]{5}{*}{ Hubei } & V11E-04 (QC, Hap 17), V11E-24 (GA, Hap21), V11E-37 (LF, Hapl), V11E-40 (LC, Hap24), V11E-43 (ES1, Hapl), V11E-47 (WUH, Hap1), V11E-48 (JL, Hapl), & Hap15: KT362859 \\
\hline & V11E-50 (LC1, Hap1), V11E-53 (LC2, Hap27), V11E-55 (DH, Hap28), V11E-6 (ES2, Hap1), V11E-77 (YM, Hap32), V11E-85 (LC3, Hap1), V11E-91 (SS, Hap1), & Hap16: КT362860 \\
\hline & V11E-119 (ES3, Hap24), V11E-136 (FBS, Hapl), V11E-140 (HS1, Hap1), V11E-143 (ES4, Hap41), V1 1E-144 (TM, Hap42), V11E-148 (ES5, Hapl), V11E-149 & $\begin{array}{ll}\text { Hap 17: KT362861 } \\
\text { Han18: KT362862 }\end{array}$ \\
\hline & $\begin{array}{l}\text { SIS, Hapl), V11E-162 (MLX, Hap47), V11E-164 (TSC, Hap49), V11E-165 (JSX, Hapl), V11E-166 (WQ1, Hap24), V11E-167 (WQ22, Hal } \\
\text { Hap50),V11E-75 (HS2, Hap16), 79-V11E0128 (BK, Hap34) }\end{array}$ & $\begin{array}{l}\text { Hap18: K1628682 } \\
\text { Hap19: KT362863 }\end{array}$ \\
\hline & & Hap20: КT362864 \\
\hline \multirow[t]{2}{*}{ Hunan } & V11E-25 (RJ1, Hapl), V11E-31 (WL, Hap53), V11E-117 (CD1, Hap7), V11E-134 (YY, Hap40), V11E-151 (CD2, Hap1), V11E-152 (RJ2, Hap1), V11E-153 (SY1, & Hap21: KT362865 \\
\hline & $\begin{array}{l}\text { Hapl), V11E-155 (CD3, Hap15), V11E-26 (RJ3, Hapl), V11E-27 (SY2, Hap1), V1 1E-32 (RJ4, Hap24), V11E-97 (NY, Hap36), V11E-111 (CD4, Hapl), V11E-112 } \\
\text { (CD5, Hapl) }\end{array}$ & Hap22: КТ 362866 \\
\hline \multirow[t]{4}{*}{ Jiangsu } & V1 lE-05 (CZ, Hapl), V1 IE-30 (LH1, Hap23), V11E-33 (HA1, Hapl), V1 IE-34 (HZEI, Hap25), V11E-35 (HA2, Hapl), V1IE-41 (LY, Hapl), V11E-45 (WX1, & Hap24: KT362868 \\
\hline & Hap1), V11E-49 (NT, Hap1), V11E-56 (YZ, Hap52), V1 lE-58 (WX2, Hap1), V1 1E-59 (YQ1, Hap1), V11E-80 (LYG, Hap24), V11E-81 (DY, Hap35), V11E-84 & Hap25: КT362869 \\
\hline & (SZ1, Hap1), V11E-86 (SZ2, Hap1), V11E-102 (YQ2, Hap37), V11E-113 (YX, Hap53), V11E-118 (NJ, H8), V11E-123 (CZ2, Hap1), V11E-137 (SZ3, Hap1), V11E- & Hap26: КT362870 \\
\hline & 150 (HZE2, Hapl), V11E-154 (LH2, Hapl), V1 1E-156 (HA3, Hapl), V11E-159 (SUY, Hapl) & $\begin{array}{l}\text { Hap27: KT362871 } \\
\text { Hap28: KT362872 }\end{array}$ \\
\hline Jiangxi & V11E-46 (JJ, Hap1), V11E-62 (LP1, Hap1), V11E-66 (JDZ, Hap1), V11E-83 (LP2, Hap1), V11E-122 (YG, Hap1), V11E-139 (SR, Hap1) & Hap29: KT362873 \\
\hline Liaoning & V11E-0 & Hap30: KT362874 \\
\hline Shandong & V11E- & Hap31: KT362875 \\
\hline Shaanxi & V11E-90 (HZ, Hap12), V111 & KT362876 \\
\hline Sichuan & $\begin{array}{l}\text { V11E-57 (QL, Hap 12), V11E-61 (CQ1, Hap29), V11E-63 (CQ2, Hap1), V11E-64 (CQ3, Hap1), V11E-82 (MS, Hap12), V11E-105 (WX, Hap1), V11E-106 (ZX, } \\
\text { Hap1), V1lE-107 (NQ, Hap1), V11E-109 (DX, Hap2), V11E-110 (FD, Hap1) }\end{array}$ & $\begin{array}{l}\text { Hap33: КT362877 } \\
\text { Hap34: KT362878 }\end{array}$ \\
\hline \multirow[t]{5}{*}{ 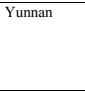 } & V11E-08 (HQ1, Hap 12), V1 lE-22 (HQ2, Hap20), V11E-23 (HQ3, Hap1), V1 lE-28 (YX1, Hap1), V11E-29 (CG1, Hap22), V11E-51 (CG2, Hap1), V1 lE-93 (ML, & Hар35: КT362879 \\
\hline & Hap 1), V11E-94 (YJI, Hap3), V11E-95 (SM, Hap4), V11E-98 (JS, Hap51), V11E-1 15 (KM, Hap6), V11E-11 (AL, Hap24), V1 IE-120 (CG3, Hap53), V1IE-127 & Нар36: КT362880 \\
\hline & (YX2, Hap1), V11E-128 (MJ1, Hap1), V11E-1294 (PER1, Hap 1), V11E-130 (P) & Нар37: КТ362881 \\
\hline & ap13), V1lE-147 (YJ2, Hap14), V11E-160 (HLT1, Hap45), V11E & Нар38: КT36 \\
\hline & V11E-104 (CO4, Hap12) & Hap39: КT36 \\
\hline Chongqing & & \\
\hline & & Hap42: КT33628036 \\
\hline \multirow{2}{*}{ Pyongyang } & V11E-169 (PR1, Hap1), V11E-170 (PR2, Hapl) & Hap43: KT362887 \\
\hline & & Hap44: КT362888 \\
\hline Japan & & Hap45: КT362889 \\
\hline \multirow{2}{*}{ Oita-ken } & V11E-39 (DF, Hapl) & Hap46: КT362890 \\
\hline & & Hap47: KT362891 \\
\hline Vietnam & & Hap48: KT362892 \\
\hline \multirow[t]{5}{*}{ Hanoi } & V11E-54 (HN1, Hapl), V11E-99 (HN2, Hapl) & Hap49: КT362893 \\
\hline & & Hap50: KT362894 \\
\hline & & Hap51: KT362895 \\
\hline & & Hap5 \\
\hline & & Hap53: KT3628 \\
\hline
\end{tabular}

XC, Xuancheng; HN, Huaining; TC, Tongcheng; QS, Qianshan; SX, Sheqian; QY, Qingyang; LJ, Lujiang; CZ, Chizhou; CH, Caohu; AQ, Anqing; NL, Nanling; YL, Yangliu; SC1, Shucheng; HF, Hefei; WH, Wuhu; PR, Pyongyang; DF, Oitaken; WYS, Wuyishan; LZ, Liuzhou; GL, Guiling; BJ, Bijie; AS, Anshun; GY, Guiyang; QX, Qianxi; ZY, Zunyi; MT, Meitan; QH, Qionghai; XY, Xinyang; NY, Nanyang; WY, Wuyang; PDS, Pingdingshan; HY, Huaiyuan; SQ, Shenqiu; HN, Hanoi; QC, Qichun; GA, Gongan; LF, Laifeng; LC, Lichuan; ES, Enshi; WUH, Wuhan; JL, Jiangling; DH, Donghu; YM, Yunmeng; SS, Shashi; FBS, Fubaoshan; HS, Huangshi; TM, Tianmen; SIS, Shishou; MLX, Maliuxi; TSC, Tusicheng; JSX, Jianshanxiang; WQ, Wenquan; XF, Xianfeng; BK, Baokang; RJ, Ruanjiang; WL, Wuling; CD, Changde; YY, Yiyang; SY, Shaoyang; NY, Ningyuan; CZ, Changzhou; LH, Liuhe; HA, Huaian; HZE, Hongze; LY, Liyang; WX, Wuxi; NT, Nantong; YZ, Yangzhou; YQ, Yuqi; LYG, Lianyungang; DY, Danyang; SZ, Suzhou; YX, Yixing; NJ, Nanjing; SUY, Suyu; JJ, Jiujiang; LP, Leping; JDZ, Jingdezhen; YG, Yugan; SR, Shangrao; PLD, Pulandian; QF, Qufu; HZ, Hanzhong; XA, Xian; CA, Changan; QL, Qionglai; CQ, Chongqing; MS, Minshan; WX, Wanxian; ZX, Zhongxian; NQ, Nanquan; DX, Daxian; FD, Fengdu; HQ, Heqing; YX, Yuxi; CG, Chenggong; ML, Mengla; YJ, Yuanjiang; SM, Simao; JS, Jianshui; KM, Kunming; AL, Anlong; MJ1, Mojiang; PER, Puer; JH, Jinghong; MH, Menghai; HLT, Heilongtan. Abbreviations for each location and haplotype name (Hap1-Hap53) are shown in parentheses following the accession number.

Eppendorf AG 22331 Hamburg Thermocycler (Eppendorf, Germany), and the PCR conditions were as according to Wang and $\mathrm{Li}(1998)$.

Following amplification, the size of each PCR product was determined electrophoretically on $2.0 \%(\mathrm{w} / \mathrm{v})$ agarose gel run at $100 \mathrm{~V}$ in $0.5 \mathrm{X}$ TBE (Tris-boric acid-EDTA), and visualized by staining with ethidium bromide. All of the PCR products were purified using a TIANquick Midi Purification Kit following the protocols provided by the manufacturer (Tiangen). Sequences were generated on an ABI 3730 automated sequencer (Applied Biosystems, Foster City, CA, USA) by Sangon Biotech using the same primers as for the amplifications. 


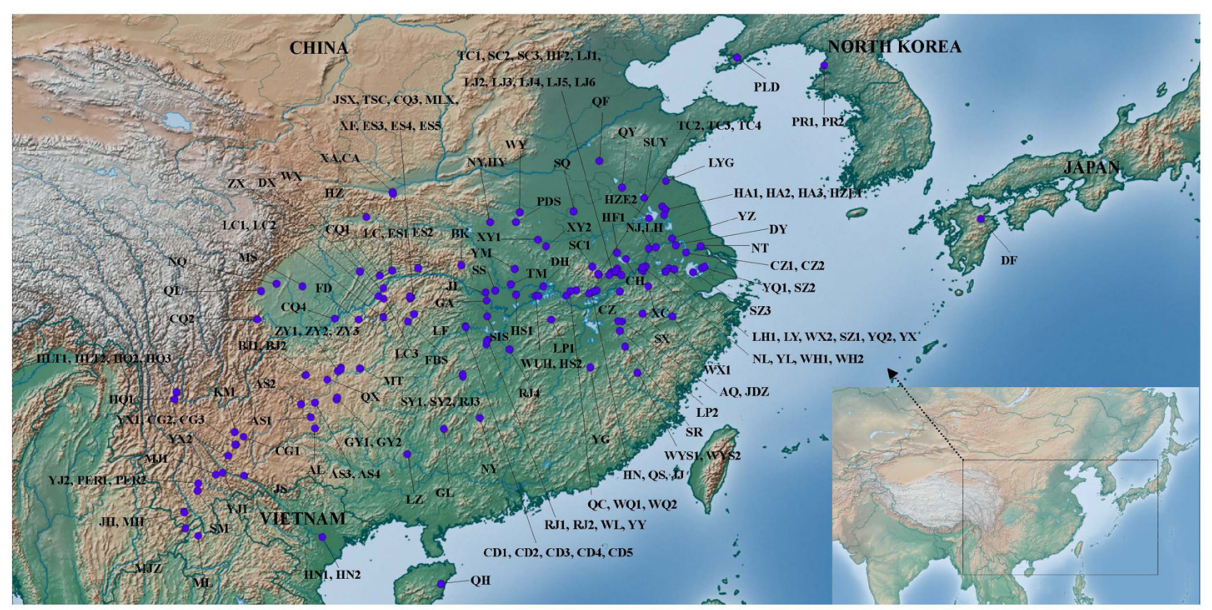

Figure 1. Sampling locations of 170 Oenanthe accessions in East Asia (Location codes as in Table 1).

Table 2. GenBank accession numbers of Oenanthe internal transcribed spacer sequences from previous studies.

\begin{tabular}{|c|c|c|}
\hline Species & GenBank accession No. & Reference \\
\hline O. javanica & AY691944 & Kadereit and Kadereit, 2005 \\
\hline O. sinensis & AY691943 & Kadereit and Kadereit, 2005 \\
\hline O. sarmentosa & AY691942 & Kadereit and Kadereit, 2005 \\
\hline O. prolifera & AY691941 & Kadereit and Kadereit, 2005 \\
\hline O. peucedanifolia & AY691940 & Kadereit and Kadereit, 2005 \\
\hline O. lachenalii & AY691939 & Kadereit and Kadereit, 2005 \\
\hline O. fistulosa & AY691938 & Kadereit and Kadereit, 2005 \\
\hline O. silaifolia & AY691937 & Kadereit and Kadereit, 2005 \\
\hline O. pimpinelloides & AY691935 & Kadereit and Kadereit, 2005 \\
\hline O. montis-khortiati & AY691934 & Kadereit and Kadereit, 2005 \\
\hline O. divaricata & AY691932 & Kadereit and Kadereit, 2005 \\
\hline O. fluviatilis & AY691930 & Kadereit and Kadereit, 2005 \\
\hline O. aquatica isolate 2 & AY691925 & Kadereit and Kadereit, 2005 \\
\hline O. aquatica isolate 1 & AY691924 & Kadereit and Kadereit, 2005 \\
\hline O. conioides isolate 3 & AY691922 & Kadereit and Kadereit, 2005 \\
\hline O. linearis subsp rivularis & JX962352 & Spalik et al., 2014 \\
\hline O. procumbens & JX962351 & Spalik et al., 2014 \\
\hline O. lisae & JX962350 & Spalik et al., 2014 \\
\hline O. linearis subsp linearis & JX962349 & Spalik et al., 2014 \\
\hline O. javanica subsp javanica & JX962348 & Spalik et al., 2014 \\
\hline O. hookeri & JX962347 & Spalik et al., 2014 \\
\hline O. prolifera & GQ379319 & Spalik et al., 2009 \\
\hline O. thomsonii & EU236186 & Zhou et al., 2008 \\
\hline O. linearis subsp rivularis & EU236185 & Zhou et al., 2008 \\
\hline O. benghalensis & EU236181 & Zhou et al., 2008 \\
\hline$O$. virgata & EU233944 & Zhou et al., 2008 \\
\hline O. silaifolia & EU233943 & Zhou et al., 2008 \\
\hline O. sarmentosa & EU233942 & Zhou et al., 2008 \\
\hline O. palustris & EU233941 & Zhou et al., 2008 \\
\hline O. millefolia & EU233940 & Zhou et al., 2008 \\
\hline O. mildbraedii & EU233939 & Zhou et al., 2008 \\
\hline O. lachenalii & EU233938 & Zhou et al., 2008 \\
\hline O. javanica subsp stolonifera & EU233937 & Zhou et al., 2008 \\
\hline O. foucaudii & EU233936 & Zhou et al., 2008 \\
\hline O. divaricata & EU233935 & Zhou et al., 2008 \\
\hline O. aquatica & EF177732 & Downie et al., 2008 \\
\hline O. sarmentosa & AY360252 & Hardway et al., 2004 \\
\hline O. pimpinelloides & AY360251 & Hardway et al., 2004 \\
\hline O. peucedanifolia & AY360250 & Hardway et al., 2004 \\
\hline O. fistulosa & AY360249 & Hardway et al., 2004 \\
\hline O. divaricata & AY360248 & Hardway et al., 2004 \\
\hline O. crocata & AY360246 & Hardway et al., 2004 \\
\hline O. banatica & AY360245 & Hardway et al., 2004 \\
\hline
\end{tabular}




\section{Sequence analysis and phylogenetic reconstruction}

Sequences were aligned using CLUSTAL W (Thompson et al., 1994). The aligned sequences were manually inspected prior to analysis, and gaps were inserted to insure positional homology. Insertions/deletions (indels) were treated as point mutations and equally weighted with other mutations. ITS haplotypes were determined from nucleotide substitutions and indels of the aligned sequences.

Bayesian inference (BI) and maximum likelihood (ML) analyses were conducted for the ITS sequence dataset, including sequences of the ITS haplotypes generated from this study and sequences from GenBank. An analysis was conducted for each of the following edited ITS sequence datasets: 1) ITS dataset without indels; 2) ITS dataset with indels, and each indel was treated as one point mutation. The Oenanthe cladogram was rooted using $C$. virosa and C. maculate var. maculate.

The BI analysis was conducted using the BEAST v. 1.7.4 program (Drummond and Rambaut, 2007) on each of the two datasets. The best-fit models (GTR + I + G) were selected according to the Akaike information criterion (Akaike, 1974) using MrModeltest 2.3 (Nylander, 2004) in conjunction with PAUP 4.0 (Swofford, 1998) to generate model scores. A starting tree was randomly generated and a Yule process was performed. Two separate Markov chain Monte Carlo analyses were run for 10,000,000 generations, with sampling at every 1000 generations to ensure that all of the effective sample size values were greater than 200. Tracer v1.5 (http://tree.bio.ed.ac.uk/software/tracer/) was used to check the parameters, and the first $10 \%$ of generations was discarded as burn-in. Bayesian trees were annotated in TreeAnnotator 1.6.0 (http://beast.bio.ed.ac.uk/TreeAnnotator) and edited in FigTree 1.3.1 (http://tree.bio. ed.ac.uk/software/figtree/).

ML phylogenetic analyses were performed on each of the two edited datasets using the PhyML v.3.0 software (Guindon et al., 2010) using the "GTR + I + G" nucleotide substitution model. Clade stability was estimated by non-parametric bootstrapping with 1000 replicates in PhyML.

\section{RESULTS}

\section{Sequence variation}

Among the 170 ITS sequences generated in this study, the complete ITS region varied in length from 619 to $622 \mathrm{bp}$. The total length of the alignment was $624 \mathrm{bp}$. A total of 101 polymorphic sites (97 substitutions and four indels) of the ITS region resulted in the resolution of 53 haplotypes (Hap1-Hap53) across the 170 accessions (from 170 locations) (Table 1). GenBank accession numbers (Nos. KT362845 to KT362897) for each haplotype are listed in Table 1. Among the 53 ITS haplotypes revealed in this study, three haplotypes (Hap1, Hap12, and Hap24) were widely distributed in the sampled region. Among the 170 Oenanthe accessions, 94 were assigned to Hap1, 11 to Hap12, and 8 to Hap24 (Table 1). In addition, 46 of the 53 haplotypes were unique.

The aligned ITS sequence matrix of the 53 haplotypes and the 43 accessions of 29 species was $559 \mathrm{bp}$ in length after removing the indels. When treating each indel as one point mutation, the total length of the ITS sequence matrix was $585 \mathrm{bp}$. These two data matrices were used in the subsequent phylogenetic analyses. 


\section{Phylogenetic analyses}

Based on the ITS sequence matrix that contained 98 aligned sequences without indels (53 from the haplotypes revealed in this study, 43 from GenBank representing 29 species, and two from the outgroup), the BI analysis revealed two clades (Clade I and Clade II) of the 53 haplotypes (Figure 2): Clade I contained 16 haplotypes (Bayesian posterior probability [PP] $<$ 0.5 ), which was closely related to O. mildbraedii; Clade II contained 37 haplotypes ( $\mathrm{PP}<0.5$ ), with three accessions of $O$. sarmentosa embedded within this clade. For the phylogeny of the whole Oenanthe genus, $O$. procumbens and $O$. palustris were strongly supported $(\mathrm{PP}=1)$ as sisters to the remainder of the ingroup taxa. Accessions from previous studies formed at least five well-supported clades ( $\mathrm{PP}=0.97-1.00)$ (Figure 2). Based on the same dataset, the ML analysis revealed a generally similar phylogenetic topology (data not shown) as the Bayesian tree, but with relatively weak bootstrap values supporting the monophyly of several clades. Two groups of Oenanthe haplotypes revealed by the ML analysis were the same as those in the BI analysis. The two groups were also shown to be closely related to O. mildbraedii and O. sarmentosa.

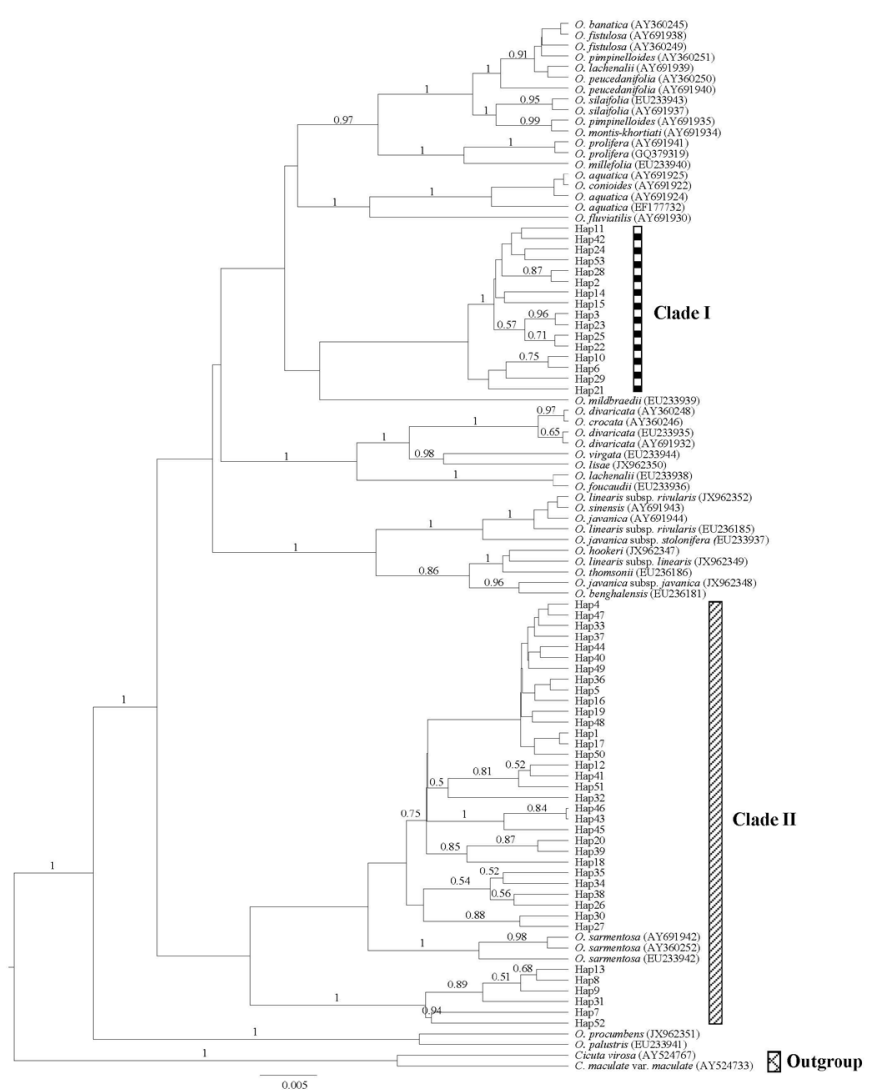

Figure 2. Majority-rule consensus tree obtained from Bayesian analyses of internal transcribed spacer (ITS) sequence data for 53 haplotypes (Hap1-Hap53) generated in the present study and 43 Oenanthe accessions of 29 species from GenBank. Posterior probabilities are indicated above branches. The indels in the ITS sequence dataset were removed. 
Based on the ITS sequence matrix that contained 98 aligned sequences with indels, the BI analysis also revealed two clades (Clade A and Clade B) of the 53 haplotypes (Figure $3)$. Clade $A(P P=0.78)$ and Clade $B(P P=0.97)$ were shown to be the sister group, with three accessions of $O$. sarmentosa basal to these two clades. Clade A contained a different haplotype number to Clade I, and Clade B contained a different number to Clade II. Based on the same dataset with indels, the ML analysis revealed an identical phylogenetic topology (data not shown) as the Bayesian tree.

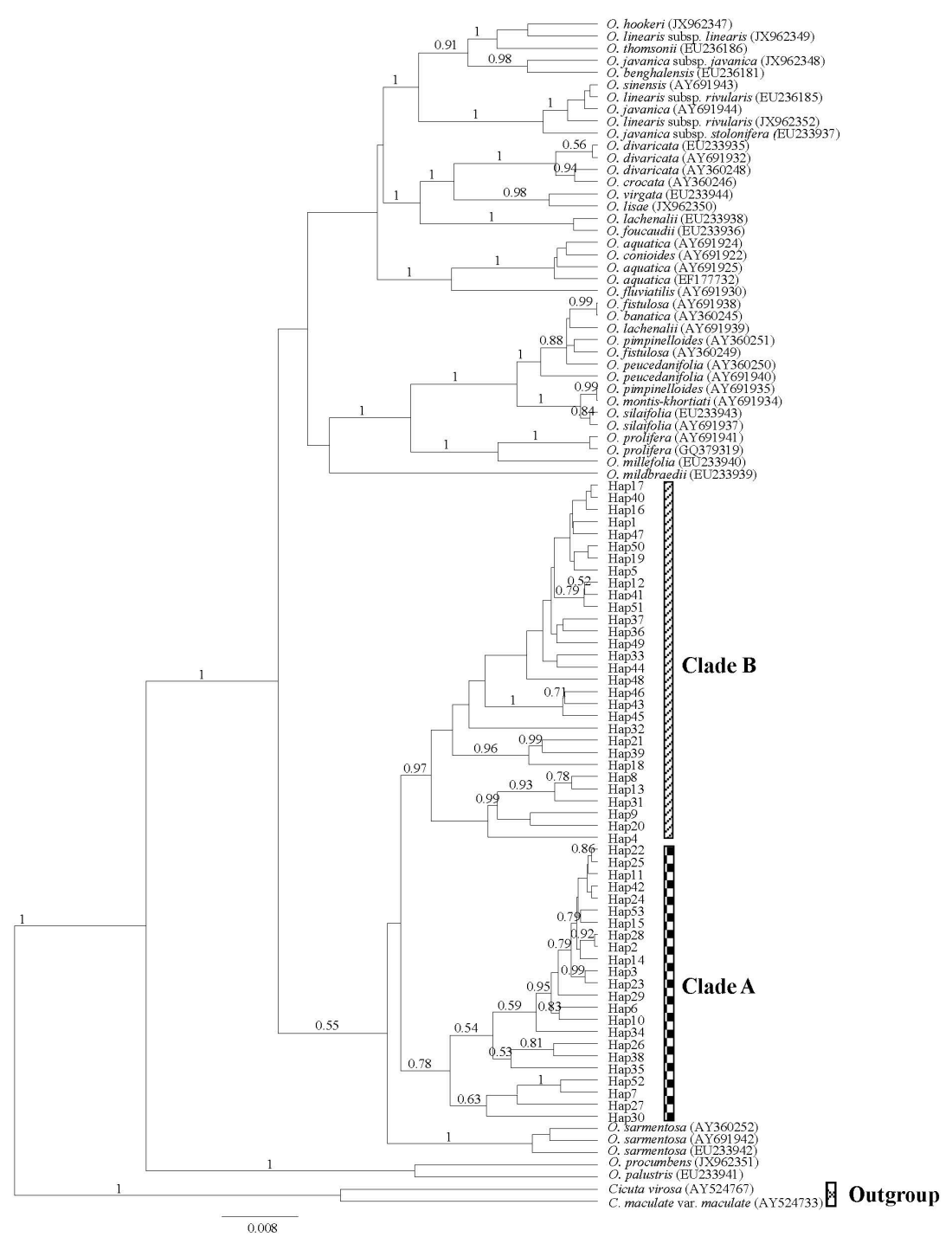

Figure 3. Majority-rule consensus tree obtained from Bayesian analyses of the internal transcribed spacer (ITS) sequence data for 53 haplotypes (Hap1-Hap53) generated in the present study and 43 Oenanthe accessions of 29 species from GenBank. Posterior probabilities are indicated above branches. The indels in the ITS sequence dataset were included. 


\section{DISCUSSION}

In this study, we compared the nrDNA ITS region sequence variation of 170 Oenanthe accessions collected from a wide geographical region of China and its neighboring countries with accessions reported in previous studies (Hardway et al., 2004; Kadereit and Kadereit, 2005; Downie et al., 2008; Zhou et al., 2008; Spalik et al., 2014). Using two phylogenetic tree construction methods (BI and ML) and two kinds of dataset (with and without indels), we found that the accessions collected in this study tended to cluster into two groups. From the phylogenetic trees, we also found that one of the two haplotype groups was close to $O$. mildbraedii and the other to $O$. sarmentosa.

To date, many gene markers have been employed in the phylogenetic study of the Apiaceae (Downie et al., 2001, 2008; Kadereit and Kadereit, 2005; Zhou et al., 2008, 2009; Spalik et al., 2009, 2014), such as nrDNA ITS region, chloroplast DNA gene ( $r b c \mathrm{~L}$ and $m a t \mathrm{~K})$, intergenic spacer (psbI-5'trnK and rps16-5'trnK), and intron (rpl16, rps16, and rpoC1) sequences. Among these, the ITS region is the most frequently used marker. The ITS region of nearly all Oenanthe species has been sequenced. Although the utility of the ITS region for high-level phylogenetic estimation in the Apiaceae has been questioned due to high rates of ITS sequence divergence among the lineages (Downie et al., 2008), at present it is the best marker for lower-level phylogenetic analyses (Downie et al., 2001; Zhou et al., 2008). In this study, we used ITS sequences from GenBank that represented all species that have been sequenced. Both the BI and ML analyses demonstrated that there are different accessions for the same species, but those sequenced in different studies were often clustered together: three accessions of $O$. sarmentosa (AY691942, AY360252, and EU233942), three accessions of O. divaricata (AY360248, AY691932, and EU233935), two accessions of O. silaifolia (EU233943 and AY691937), and two accessions of O. prolifera (AY691941 and GQ379319), which shows that the ITS region is a powerful tool for species identification in Oenanthe.

Unexpectedly, none of the 53 ITS haplotypes identified in the 170 Oenanthe accessions sampled in this study were close to O.javanica, which is regarded as the most widely cultivated and used vegetable in the genus in East Asia (Huh et al., 2002; Zhao, 2010). Instead, the two haplotype groups revealed in our phylogenetic analyses were close to $O$. mildbraedii and $O$. sarmentosa. These two species have never been recorded in China (China Flora Editorial Board of CAS, 1985; Fu and Watson, 2005) or its neighboring countries (Huh et al., 2002); therefore, it seems probable that in these sampled locations, Oenanthe accessions have been given the incorrect name, O. javanica. The morphology of $O$. javanica is highly variable, and the size and shape of the leaves of the $O$. javanica subspecies javanica converge with those of the $O$. javanica subspecies rosthornii in Malaysia and adjoining areas; in addition, $O$. benghalensis and $O$. linearis have been placed within the broader species concept for $O$. javanica by some workers (Fu and Watson, 2005).

It should be noted that although our sampling range covered a large proportion of the geographical range of Oenanthe species in East Asia, in each location we only sampled one individual, and other important Oenanthe areas were not sampled; therefore, it is possible that locations where $O$. javanica is present in East Asia were not sampled. In addition, only a few accessions of most of the recorded species in Oenanthe, including O.javanica, O. mildbraedii, and $O$. sarmentosa, were sequenced for the ITS region. Small sample sizes and a lack of morphological information of species outside East Asia are limitations of our comparative taxonomic study. Future studies should carefully check the morphological characteristics of 
other Oenanthe species and sequence their ITS regions in order to clarify the taxonomic status of the genus.

\section{Conflicts of interest}

The authors declare no conflict of interest.

\section{ACKNOWLEDGMENTS}

Research supported by the National Nature Science Foundations of China (\#31270278).

\section{REFERENCES}

Akaike H (1974). A new look at the statistical model identification. IEEE Transact. Automatic Control 19: 716-723. http:// dx.doi.org/10.1109/TAC.1974.1100705

China Flora Editorial Board of CAS (1985). Flora of China. Vol. 52. Science Press, Beijing.

Downie SR and Katz-Downie DS (1999). Phylogenetic analysis of chloroplast rps 16 intron sequences reveals relationships within the woody southern African Apiaceae subfamily Apioideae. Can. J. Bot. 77: 1120-1135. http://dx.doi. org $/ 10.1139 / \mathrm{b} 99-086$

Downie SR, Plunkett GM, Watson MF, Spalik K, et al. (2001). Tribes and clades within Apiaceae subfamily Apioideae: the contribution of molecular data. Edinb. J. Bot. 58: 301-330. http://dx.doi.org/10.1017/S0960428601000658

Downie SR, Katz-Downie DS, Sun FJ and Lee CS (2008). Phylogeny and biogeography of Apiaceae tribe Oenantheae inferred from nuclear rDNA ITS and cpDNA psbI-5'trnK (UUU) sequences, with emphasis on the North American Endemics clade. Botany 86: 1039-1064. http://dx.doi.org/10.1139/B08-055

Drummond AJ and Rambaut A (2007). BEAST: Bayesian evolutionary analysis by sampling trees. BMC Evol. Biol. 7: 214.http://dx.doi.org/10.1186/1471-2148-7-214

Fu FT and Watson MF (2005). Oenanthe L. In: Flora of China (China Flora Editorial Board of CAS, ed.). Science Press and Missouri Botanical Garden Press, Beijing and St. Louis, pp. 130-132.

Guindon S, Dufayard JF, Lefort V, Anisimova M, et al. (2010). New algorithms and methods to estimate maximumlikelihood phylogenies: assessing the performance of PhyML 3.0. Syst. Biol. 59: 307-321.http://dx.doi.org/10.1093/ sysbio/syq010

Hardway TM, Spalik K, Watson MF, Katz-Downie DS, et al. (2004). Circumscription of Apiaceae tribe Oenantheae. $S$. Afr. J. Bot. 70: 393-406. http://dx.doi.org/10.1016/S0254-6299(15)30222-2

Huh MK, Choi JS, Moon SG and Huh HW (2002). Genetic diversity of natural and cultivated populations of Oenanthe javanica in Korea. J. Plant Biol. 45: 83-89. http://dx.doi.org/10.1007/BF03030288

Kadereit G and Kadereit JW (2005). Phylogenetic relationships, evolutionary origin, taxonomic status, and genetic structure of the endangered local Lower Elbe river (Germany) endemic Oenanthe conioides (Nolte ex Rchb.f.) Lange (Apiaceae): ITS and AFLP evidence. Flora 200: 15-29. http://dx.doi.org/10.1016/j.flora.2004.07.001

Li DZ, Gao LM, Li HT, Wang H, et al; China Plant BOL Group (2011). Comparative analysis of a large dataset indicates that ITS should be incorporated into the core barcode for seed plants. Proc. Natl. Acad. Sci. USA 108: 19641-19646. http://dx.doi.org/10.1073/pnas.1104551108

Liu HW, Gao MX and Rao GZ (2007). A comparison of nutritive components in Apium graveolens and wild Oenanthe javanica plants. Chin. Wild Plant Resour. 26: 36-38.

Nylander JAA (2004). MrModeltest v2. Evolutionary Biology Centre, Uppsala University.

Spalik K, Downie SR and Watson MF (2009). Generic delimitations within the Sium alliance (Apiaceae tribe Oenantheae) inferred from cpDNA rps 16-5' $\operatorname{trnK}$ (UUU) and nrDNA ITS sequences. Taxon 58: 735-748.

Spalik K, Banasiak L, Feist MAE and Downie SR (2014). Recurrent short-distance dispersal explains wide distributions of hydrophytic umbellifers (Apiaceae tribe Oenantheae). J. Biogeogr. 41: 1559-1571. http://dx.doi.org/10.1111/ jbi. 12300

Su CH, Chen XN, Yang XB, Huang ZM, et al. (2011). Study on the anti-fatigue effect of the extract of Oenanthe javanica and its probable mechanism in mice. Pharm. J. Chin. PLA 27: 103-106.

Swofford DL (1998). PAUP*: phylogenetic analysis using parsimony (*and other methods), version 4. Sinauer, Sunderland, Massachusetts, USA. 
Thompson JD, Higgins DG and Gibson TJ (1994). CLUSTAL W: improving the sensitivity of progressive multiple sequence alignment through sequence weighting, position-specific gap penalties and weight matrix choice. Nucleic Acids Res. 22: 4673-4680.http://dx.doi.org/10.1093/nar/22.22.4673

Wang XQ and Li ZY (1998). The application of sequence analysis of rDNA fragment to the systematic study of the subfamily Cyrtandroideae (Gesneriaceae). Acta Phytotaxon. Sin. 36: 97-105.

White TJ, Bruns T, Lee S and Taylor J (1990). Amplification and direct sequencing of fungal ribosomal RNA genes for phylogenetics. In: PCR protocols: a guide to methods and applications (Innis MA, Gelfand DH, Sninsky JJ and White TJ, eds.). Academic Press, San Diego, CA, USA, 315-322.

Zhao SH (2010). Analysis on relationships of Oenanthe germplasm resource. Master's thesis, Yangzhou University, Yangzhou.

Zhou J, Peng H, Downie SR, Liu ZW, et al. (2008). A molecular phylogeny of Chinese Apiaceae subfamily Apioideae inferred from nuclear ribosomal DNA internal transcribed spacer sequences. Taxon 57: 402-416.

Zhou J, Gong X, Downie SR and Peng H (2009). Towards a more robust molecular phylogeny of Chinese Apiaceae subfamily Apioideae: additional evidence from nrDNA ITS and cpDNA intron ( $r p l 16$ and rps16) sequences. Mol. Phylogenet. Evol. 53: 56-68.http://dx.doi.org/10.1016/j.ympev.2009.05.029 